Ensino, Saúde e Ambiente - V5 (3), pp. 44-54, dez. 2012

\title{
A CONSTRUÇÃO DA IMAGEM CORPORAL ENTRE JOVENS DO ENSINO FUNDAMENTAL: A QUESTÃO DA IDENTIDADE E DA DIFERENÇA E O PAPEL DO PROFESSOR.
}

\section{THE CONSTRUCTION OF BODY IMAGE AMONG YOUNG ELEMENTARY SCHOOL: THE QUESTION OF IDENTITY AND DIFFERENCE AND THE CONSEQUENCES FOR FEEDING BEHAVIOR AND HEALTH.}

\section{Fernanda Roberta Daniel da Silva Portronieri e Alexandre Brasil Carvalho da Fonseca} Núcleo de Tecnologia Educacional para a Saúde - Universidade Federal do Rio de Janeiro

\section{RESUMO}

Esse estudo apresenta uma discussão da construção da imagem corporal entre jovens estudantes. Trata-se de uma etnografia escolar por nove meses em duas turmas de uma escola no Rio de Janeiro. Os resultados apontaram para a influência da opinião dos professores na formação de identidade dos alunos e no processo de construção da imagem corporal destes. A visão que os professores têm passado para seus alunos reflete a "ditadura da magreza", reforçando a idéia de que a identidade está relacionada à magreza e a diferença à obesidade e, dessa forma, os alunos almejam pertencer "às normas", "ser a identidade". Como a alimentação está fortemente relacionada as formas corporais, os jovens lançam mão desse instrumento para modificarem seus corpos de forma acrítica e sem pensar nas consequências para a saúde.

Palavras-chave: formação de identidade, educação em saúde na escola, imagem corporal

\begin{abstract}
This study presents a discussion on the social construction of body images and its influence upon people's food choices and health. The research was carried out with students from a public elementary school in Rio de Janeiro city. It was a school ethnography with 9 months duration, and a total of 20 hours a week. The results pointed to the great influence of the teachers' opinions on the establishment of students' identities and, therefore, on the process of constructing their body images. The view that teachers give to their students reflects the dictatorship of thinness imposed by society, reinforcing the idea that identity is related to thinness and obesity to the differences and thus, students want to belong to "the rules", "be the identity". The food is directly related to body shapes, the young people to use this to change their bodies uncritically and without considering the consequences for health.
\end{abstract}

Key words: identity formation, school health education, body image

\section{Introdução}

Esse artigo faz parte de uma dissertação de mestrado que buscou entender como se dá a construção da imagem corporal de alunos de uma escola pública da rede municipal do Rio de Janeiro e a sua influencia nas escolhas alimentares. Discute-se 
parte dos resultados dessa pesquisa, traçando a relação da formação da imagem corporal dos jovens com a construção da sua identidade, bem como a influencia das escolhas alimentares para definição da mesma.

O autor David Le Breton, em seu livro "Sociologia do corpo" (2006) traz uma série de discussões sobre o significado do corpo nas relações sociais. Diz que o corpo é moldado pelo contexto social em que o ator se insere e ainda que o corpo é a evidência primeira da relação do ator com o mundo.

Alguns pontos da obra de Le Breton (2006) são fundamentais em uma discussão sobre percepção corporal: o primeiro é que a expressão corporal é socialmente modulável, mesmo sendo vivida com o estilo particular do indivíduo; o segundo é sobre a redução da existência humana ao corpo e sua forma de apresentação e expressão; a terceira diz respeito às mudanças que ocorrem na expressão corporal de acordo com os tempos e culturas; o quarto ponto discorre sobre a apologia ao corpo opondo o ator a si próprio; e por último a influência da mídia e da moda na forma de apresentação corporal: a aparência.

Quando Le Breton afirma que a expressão corporal é socialmente modulável inclui desde modos de comportamento, gestos na comunicação, expressões verbais, formas de vestimentas e uso de acessórios até meios de modificação corporal como tatuagens, perfurações (brincos ou outros objetos), alongamento de alguma parte do corpo (como o pescoço, por exemplo), engordar ou emagrecer. Todas essas são formas de expressão corporal que se modificam em função de um conjunto de sistemas simbólicos. Essas marcas corporais preenchem funções diferentes em cada sociedade, chamando atenção para os valores específicos da mesma. A forma como o corpo percebe os inúmeros estímulos é função do pertencimento social do ator e de seu modo particular de inserção cultural. O autor afirma que independente do lugar e da época em que se nasça uma criança e até mesmo das condições sociais do país, a mesma está predisposta inicialmente a interiorizar e a reproduzir os traços físicos particulares de qualquer sociedade humana (Le Breton, 2006, p. 8).

Nesse sentido, Le Breton traz a discussão da importância da influência dos demais atores, "dos outros", nas atitudes corporais do indivíduo. A modificação da corporalidade é uma forma de marcação social, de pertencimento a um determinado grupo com certas características de expressão corporal. "Não importam quais sejam as circunstâncias da vida social, uma etiqueta corporal é usada e o ator a adota 
espontaneamente em função das normas implícitas que o guiam" (Le Breton, 2006; p. 47 - grifo meu). Afirma ainda que certos sinais corporais escapam totalmente do controle da vontade ou da consciência do ator, por influências sócio-culturais, dentro da trama social de sentidos na qual o mesmo está inserido.

A segunda discussão é sobre a redução da existência ao corpo. Le Breton, ao citar Mauss, diz que o corpo é o primeiro e mais natural instrumento do homem. Porém, o corpo é visto como a totalidade do homem, assim, socialmente o homem é julgado pelo o que ele é na sua expressão corporal. Nas sociedades modernas houve a superposição da "alma" pelo "corpo", do invisível pelo visível. "Destacado do homem, transformado em objeto a ser moldado, modificado, modulado conforme o gosto do dia, o corpo se equivale ao homem, no sentido em que, se modificando as aparências, o próprio homem é modificado" (Le Breton, 2006; p.87 - grifo nosso).

A equivalência dada à moral pela apresentação do físico é um sistema implícito de valores simbólicos. Assim, a aparência física é colocada sob julgamento do outro de acordo com os estereótipos que são estabelecidos dentro de uma sociedade, e estigmatizada de imperfeição moral ou de pertencimento a um determinado grupo social. O mesmo autor diz que corpo do ser humano é o que o define socialmente perante aos olhos dos outros, assim, sua história pessoal pouco influencia na imagem que fazem do homem como um todo e sim o contrário, a imagem corporal do ator acaba determinando suas condições existenciais, perante aos olhos do "pré-conceituoso". Le Breton (2006; p. 72 - 73) diz ainda que nas sociedades ocidentais os "defeitos" tornamse estigmas e motivos para a avaliação negativa da pessoa.

Porém, a expressão corporal não é homogênea e linear; sofre alterações com o decorrer dos anos bem como são observadas peculiaridades de uma sociedade para a outra. O corpo é o efeito de uma elaboração social e cultural, e, diferentes condições de socialização modificaram profundamente, de uma geração para a outra, as formas gestuais de certos grupos sociais, o que mostra que o homem é socialmente criador dos movimentos e expressões do corpo. Dessa forma, aos órgãos e às funções do corpo humano são atribuídos representações e valores diferentes de uma sociedade para outra.

Na cultura ocidental contemporânea, a magreza simboliza competência, sucesso, controle e atrativos sexuais, enquanto excesso de peso e obesidade representam preguiça, indulgência pessoal e falta de autocontrole e força de vontade. Mas essa importância dada à magreza corporal é relativamente recente; não é preciso olhar muito 
atrás na história para ver que na Renascença havia uma valorização das mulheres de corpos mais robustos, com quadris grandes bem como os abdomens; muitas sociedades africanas valorizam o sobrepeso como símbolo de prosperidade; a burguesia francesa do século XIX associava uma boa barriga com respeitabilidade.

Principalmente quem segue a moda, faz dietas com objetivo de conseguir uma magreza que na maioria das sociedades tradicionais seria considerada como um símbolo de esterilidade e até acusações de bruxaria (De Garine, 2002). Até nas épocas em que se desejava esconder mais o corpo, outras formas eram usadas, como os espartilhos para acentuar a cintura, ou na década de 1920 quando se usavam faixas para tornar o tórax mais achatado e os seios menos aparentes. Atualmente, dietas, exercícios físicos, cirurgias plásticas são os principais meios de se modificar o corpo, além de que alterar a cor e a estrutura dos fios de cabelo, bem como a utilização de produtos cosméticos, tornou-se amplamente utilizado com o mesmo fim.

O terceiro ponto nessa discussão é a apologia ao corpo. Le Breton traz a discussão da dualidade da apologia ao corpo, pois o ator social supõe uma existência para o corpo separada da existência do homem. Dessa forma, disposto a qualquer custo a atingir o que se espera com o corpo, o ator opõe-se a si mesmo de maneira abstrata. Aqui é pertinente a discussão de como o corpo, sendo lugar do contato primeiro com o mundo, está segundo sob "a luz dos holofotes" de uma sociedade de tipo individualista.

Conti et al (2005) relatam que atualmente fatores sociais como a mídia, que vincula o ideal de magreza com felicidade e sucesso, bem como a "estigmatização" da obesidade, são as principais causas que alteram a percepção corporal, em especial para indivíduos do gênero feminino. A imagem que a pessoa tem do seu próprio corpo pode ter uma grande influência nos seus hábitos alimentares (Loureiro, 2004), pois motivada pelo desejo de emagrecer ou engordar, estando insatisfeita com a imagem corporal, a pessoa tende a fazer dietas "milagrosas", deixar de comer, comer excessivamente, ou apenas modificar seus hábitos alimentares na tentativa de obter o ideal de corpo almejado.

$\mathrm{O}$ ato de comer nos é apresentado habitualmente como um fato simplesmente biológico e natural; que necessitamos comer para sobreviver, para desempenhar as funções do organismo de forma correta, para desempenharmos atividades, para termos energia. A cotidianidade do ato alimentar acaba o neutralizando e o tira da esfera da reflexão, mas é muito importante tentar trazê-lo para essa esfera (Aguirre, 2004). Comer 
é também uma forma de se comunicar com as outras pessoas, por isso comemos determinados alimentos em certas ocasiões e não em outras, como é o caso de festas, aniversários, velórios, ou de acordo com o sexo, com a idade, enfim, podemos comunicar nosso interesse aos nossos amigos e colegas compartilhando com eles uma refeição. Da mesma forma, uma refeição pode ser agradável ou não, de acordo com a companhia, com o momento, com a própria comida. Portanto, a alimentação humana está repleta de significados e significações e todas as comidas estão mais relacionadas a essa rede de significações do que com as necessidades biológicas do corpo humano.

Assim como podemos nos expressar através das comidas, comer pouco ou comer demasiadamente também se constituem mensagens destinadas a outras pessoas e instituições, de tal forma que essas condutas ou até mesmo o peso corporal e suas formas podem expressar tanto uma informação a respeito dos hábitos alimentares quanto da personalidade, as intenções e inclusive o status social dessa pessoa (Contreras e Gracia Arnáiz, 2002). Ser gordo e ser magro na sociedade contemporânea atual têm significados muito mais amplos do que simplesmente o peso corporal; com a estigmatização da obesidade (Fischler, 1995), ser magro tem significado sinônimo de saúde, de beleza, de prestígio, de sucesso, ao passo que ser gordo ganha a conotação de preguiça, fracasso, desleixo pessoal. Entender como os jovens percebem e significam seus corpos pode indicar limites e possibilidades para se pensar a educação em saúde na escola no que tangem os temas corpo, alimentação e formação de identidade.

\section{Metodologia}

Trata-se de uma etnografia escolar, focalizando especialmente o professor, o aluno e a relação entre os mesmos. A etnografia estuda como os indivíduos compreendem e estruturam seu dia-a-dia e a sua principal preocupação é o significado que têm as ações e os eventos para as pessoas ou os grupos estudados. É uma tentativa da descrição da cultura (André, 2007; p. 19). A pesquisa ocorreu em uma escola da sétima Coordenadoria Regional de Educação, no município do Rio de Janeiro. O trabalho de campo teve duração de 9 meses e a permanência na escola foi de três dias por semana, contemplando as aulas de ciências, de educação física, a merenda (recreio), a entrada e a saída dos alunos, bem como os demais espaços de socialização dos mesmos. Foram escolhidas duas turmas, uma de oitavo ano, com alunos entre 13 e 14 anos (no turno da manhã) e uma de nono ano (do turno da tarde), com alunos entre 15 e 
18 anos. Utilizou-se a observação participante de toda a rotina escolar com registro em diário de campo e entrevistas em profundidade com os professores acompanhados e com a diretora, que foram posteriormente transcritas. A pesquisa foi submetida ao Comitê de Ética da Secretaria Municipal da Saúde e teve aprovação em 30/03/2009 (CAAE: $\mathrm{n}^{\circ}$ 0032.0.314.000-09). Os participantes tiveram seu anonimato assegurado e só participaram após lerem e assinarem o termo de consentimento livre e esclarecido.

\section{Resultados}

A relação social se mostrou fortemente relacionada com a percepção corporal dos alunos. Em diversos momentos, relacionados ou não com o tema alimentação ou corpo, as falas dos alunos sempre colocam o corpo "sob a luz dos holofotes". Em alguns momentos e falas é fácil relacionar o convívio social com "o outro" e "a percepção corporal de si" e como isso influencia na forma de resposta daquele que se percebe com os olhos alheios:

"Os outros me acharem gorda é uma coisa. Agora, terem certeza disso com o meu peso registrado ali é outra completamente diferente. Não quero” (Aluna manhã - se justificando para não aferir peso e altura)

"Ser gordo não é normal?” (Aluno, manhã, se referindo á forma de nomenclatura que estava no livro sobre os índices de Massa Corporal, na qual o "Eutrófico" vinha classificado como "Normal")

Essas falas mostram a importância dada ao peso na percepção corporal e mais do que isso, a importância da opinião dos outros quanto à forma corporal de cada um. Silva (2000) em seu livro "Identidade e Diferença", diz que toda identidade adquire um sentido por meio da linguagem e dos sistemas simbólicos pelos quais eles são representados e dessa forma, a construção da identidade é tanto simbólica quanto social. As identidades são construídas a partir de outras identidades, e essa construção aparece mais na forma de oposições binárias, que é a forma mais extrema de marcar a diferença. Silva (2000) diz que onde existe a diferenciação, aí está presente o poder, que pode ser reconhecido nas seguintes marcas: incluir/excluir (estes pertencem, aqueles não); demarcar fronteiras ("nós" e "eles"); classificar ("bons" e "maus", "puros" e "impuros", “desenvolvidos" e "primitivos", "racionais" e "irracionais"); normalizar ("nós somos 
normais", "eles são anormais"). Portanto, a afirmação de identidade e de diferença implica sempre em operações de incluir e excluir, que partem sempre do ponto de vista da identidade.

Isso quer dizer que para os alunos dessa escola, há figuras que para eles representam "poder" e a partir disso se estabelece o que é a Identidade e o que é a Diferença. É inegável que a mídia exerce, hoje, um poder incomensurável no que tange à discriminação do que é bom ou mau, feio ou bonito, certo ou errado. No entanto, não podemos esquecer que além dos ídolos e suas mensagens na mídia, há personagens muito mais próximos a eles que exercem a mesma, senão uma maior força no que diz respeito à formação de opinião, identidade, percepção de si: os familiares, os pares e os professores. Como nessa pesquisa foram observadas a relação de pares na escola e a relação com o professor, são essas as relações aqui discutidas. As falas abaixo expressam a opinião dos professores, durante dias variados no decorrer do estudo sobre "ser gordo" e "ser magro":

“A Isabel era bem gordinha até o ano passado, já era bonitinha, mas depois do estirão, ficou magrinha, tá linda! Então, gente, quem ainda não passou pelo estirão, não precisa se preocupar, porque as gordurinhas acabam se espalhando quando a gente cresce! (Professora de Ciências - Manhã - durante a aula sobre a adolescência - grifo nosso).

“A Camila é gordinha, mas até é boa aluna!” (Professor de Educação Física Manhã - grifo nosso).

"Ontem teve uma menina que não quis participar das aulas de educação física. Ela além de não fazer a aula, não queria tirar o casaco por nada, e tava um calor de $40^{\circ}$. Aí eu perguntei pra ela porque ela não queria fazer a atividade física, e ela disse que tava com vergonha, porque está acima do peso. Eu conversei com ela, falei pra ela não dar bola pra o que os outros alunos pensam dela e disse também... que a atividade física é importante pra ela até perder peso, e ser magrinha." (Fala da diretora da escola - narrando um acontecimento do dia anterior - grifo nosso) 
Pode-se observar nessas falas que os professores, até mesmo em aula, mostram que ser magro é melhor ou mais bonito do que ser gordo. Até mesmo na fala da diretora, quando a mesma diz para aluna não se preocupar com o que os outros alunos pensam (“não dar bola pra eles") termina a frase de forma paradoxal, dizendo que seria importante ela fazer a atividade física para emagrecer (“ficar magrinha”).

A representação da identidade e da diferença está diretamente relacionada a quem tem o poder, e a partir disso, ocorre a atribuição de sentido. É, portanto, por meio da representação que a identidade e a diferença adquirem sentido e se ligam a sistemas de poder. "Quem tem o poder de representar tem o poder de definir e determinar a identidade". Por isso, questionar a identidade e a diferença significa questionar o sistema de representação que lhe dá sustentação (Silva, 2000; p. 91). Sendo os professores referenciais de poder para os alunos, e a partir daí, eles passam a transmitir para os seus alunos o que seria a identidade ("ser magro") e o que seria a diferença ("ser gordo").

"Fixar uma determinada identidade como norma é uma das formas privilegiadas de hierarquização das identidades e das diferenças. A normalização é um dos processos mais sutis pelos quais o poder se manifesta no campo da identidade e da diferença. Normalizar significa eleger arbitrariamente - uma identidade específica como o parâmetro em relação ao qual outras identidades só podem ser avaliadas de forma negativa. A identidade normal é "natural", desejável, única. A força da identidade normal é tal que ela nem sequer é vista como uma identidade, mas simplesmente como a identidade. Paradoxalmente, são as outras identidades que são marcadas como tais. (...) A força homogeneizadora da identidade normal é diretamente proporcional à sua invisibilidade” (Silva, 2000; p. 83)

Como foi visto nas falas acima, os professores "elegeram" como identidade o "ser magro", mesmo que isso tenha ocorrido de forma inconsciente. Querer "normalizar" os alunos com um padrão corporal influencia na forma como os mesmos percebem seus corpos e agem para modificá-lo ou não, ou simplesmente na forma como lidam com certos aspectos cotidianos. A partir desse sentimento de não pertencer "à 
norma", surge um sentimento em alguns alunos de modificar o próprio corpo antes de poder pertencer às atividades e ao grupo social:

“Deixa só eu emagrecer pra você ver quem é a baleia branca!” (Aluna manhã)

"O dia que eu conseguir emagrecer elas vão ter que me engolir" (Aluna tarde)

Le Breton (2008) diz que o corpo, muitas vezes, é colocado como um alter ego que carrega em si a parte ruim, um rascunho a ser corrigido. Nessa visão, o corpo é dissociado do homem, é considerado como um em si (Le Breton, 2008; p. 17). Essa visão cria também a idéia de maleabilidade de si através da plasticidade do corpo. " $O$ corpo tornou-se a prótese de um "eu” eternamente em busca de uma encarnação provisória para garantir um vestígio significativo de si” (Le Breton, 2008; p. 29). Na busca pelo controle do corpo, de acordo com as normas implícitas que a sociedade determina de tempos em tempos, segundo Le Breton, está a preocupação de modificar o olhar sobre si e o olhar dos outros a fim de sentir-se existir plenamente. Ao mudar o corpo, é a própria vida que o indivíduo anseia mudar, modificar seu sentimento de identidade, como se dispensando um corpo antigo, a pessoa pudesse renascer, ressignifcar-se, uma vez que é no seu corpo que a pessoa é julgada e significada.

O desejo por emagrecer está, por parte desses atores sociais, intimamente ligados com a opinião dos demais atores, numa busca de pertencimento a uma Identidade prédeterminada e aceita de forma acrítica. A preocupação com a forma física e com a alimentação, contudo, acaba se redefinindo de forma mais complexa visando a atender o olhar alheio em busca de um reconhecimento social e pertencimento à Norma. Isso influencia o comportamento alimentar, sem que seja posto em questão o gosto pessoal pela aparência física, as questões culturais de cada indivíduo relacionadas à alimentação e à percepção corporal e ignorando até mesmo questões de saúde, constituindo-se num possível campo fértil para o desenvolvimento de transtornos alimentares ou prejudicando a saúde de diversas formas.

"Desde quando eu emagreci 10 kilos, eles têm me escolhido pra jogar futebol. E pensa que foi fácil? Ficava sem comer e treinava que nem um maluco.”(Aluno manhã)

"Eu quero ser modelo. Alta eu já sou, magra também. E para alcançar meu sonho faço o impossível para continuar magra (risos)." (Aluna tarde - 14 anos) 


\section{Ensino, Saúde e Ambiente - V5 (3), pp. 44-54, dez. 2012}

\section{Considerações Finais}

A forma como a sociedade contemporânea atual tem significado a magreza e a obesidade influencia a forma como os jovens dessa escola percebem e almejam as formas corporais e, consequentemente, na alimentação dos mesmos. Não obstante, o presente trabalho concluiu que a própria escola tem contribuído para a propagação acrítica do que é belo ou feio, bom ou ruim, pautado nas determinações da sociedade que muitas vezes possui realidade bem adversa à dos alunos. A escola deve ser capaz de oferecer oportunidades para que as crianças e os jovens desenvolvam pensamentos e atitudes críticas através do questionamento dos sistemas e das formas dominantes de representação da identidade e da diferença. Em meio às adversidades da escola e às limitações a ela referentes e até mesmo em meio às limitações dos alunos, é necessário buscar formas de se estabelecer a discussão das formas dominantes de poder a fim de emancipar esses alunos no que diz respeito à "obrigatoriedade" em ser magro. Nesse sentido, a pedagogia e o currículo devem tratar a identidade e a diferença como questões de política, além de trabalhar a questão de quais mecanismos e instituições estão ativamente envolvidos na criação da identidade e de sua fixação.

A escola é um lugar de excelência para a promoção da saúde, principalmente através da educação, e deve-se utilizar de todos os espaços formais e não formais para isso. Um desses espaços privilegiados para se pensar a educação alimentar e a discussão sobre a imagem corporal e a promoção de saúde nesse contexto é o Programa Nacional de Alimentação Escolar. Segundo o Conselho Federal de Nutrição (1995), a merenda escolar adquire características de ferramenta educativa, que pode e deve ser utilizada para os fins maiores da educação habilitando o aluno a intervir na própria realidade.

Contudo, ficou claro que os professores e demais funcionários da escola influenciam de forma significativa a opinião dos alunos desse estudo e consequentemente suas atitudes. Diferente do que os mesmos imaginavam, o professor representa um ídolo, cuja opinião é importante de ser ouvida e seguida, mesmo em meio as adversidades do contexto da escola ou até mesmo das atitudes peculiares a essa faixa etária, que normalmente são de aparente resistência e contrariedades. No final do estudo na escola, em conversas com os professores, os mesmos ficaram surpresos em perceber como são influencias na vida e nas escolhas desses alunos. Discutir questões sobre alimentação, corpo e saúde os fizeram parar para refletir nas questões para além das já 
levantadas tão frequentemente pela mídia e pensar numa prática educativa em saúde mais crítica.

\section{Bibliografia}

Aguirre, P. Ricos flacos y gordos pobres. La alimentación em crisis. Capital Intelectual, Argentina, 2004.

André, M. E. D. A. Etnografia da Prática Escolar. 13. ed. Campinas - Sp: Papirus, 2007.

Conselho Federal de Nutricionistas. Panorama da Alimentação Escolar. Brasília, 1995. (Ofício CFN n.223/95)

Conti, MA; Frutuoso, MFP; Gambardella, AMD. Excesso de peso e insatisfação corporal em adolescentes. Revista de Nutrição, Campinas, 18(4): 491-497, jul - ago, 2005.

Contreras, J; Gracia Arnáiz, M. Alimentación y Cultura. Perspectivas antropológicas. Alfaomega, México, 2002.

De Garine, I. Los aspectos socioculturales de la nutrición. In: CONTRERAS, Jesus (org.). Alimentación y cultura. Alfaomega, México, 129-170; 2002.

Fischler, C. El (h)omnívoro, el gusto, la cocina y el cuerpo. Anagrama, 1995.

Le Breton, D. A sociologia do corpo. Rio de Janeiro: Vozes, 2006.

Le Breton, D. Adeus ao corpo. 3 ed. Campinas-SP: Papirus, 2008.

Loureiro, I. A importância da educação alimentar: o papel das escolas promotoras de saúde. Revista Portuguesa de Saúde Pública. 22 (2); jul - dez, 2004.

Mintz, S. W. Comida e antropologia: uma breve revisão. Revista Brasileira de Ciências Sociais, 16(47), 2001.

Silva, T. T. Identidade e diferença: a perspectiva dos estudos culturais. Vozes, 2000 . 